\title{
El currículo oculto en los libros de historia de México en el Bachillerato mexicano.
}

por José Orestes Magaña Hidalgo

Instituto de Estudios Avanzados Siglo XXI, México

joseorestes@hotmail.com

Recibido: 28/02/2019 - Aceptado: 01/06/2019

\section{Resumen}

Esta investigación analiza el contenido didáctico de los libros de texto de Historia de México a nivel bachillerato. Se empleó una metodología cualitativa de tipo descriptivo. El uso del Análisis del Discurso $(\mathrm{AD})$ permitió identificar el contexto político, económico y educativo bajo el cual se definen los contenidos de los libros de texto, así como de la participación de editoriales extranjeras que forman parte en este proceso y cuya intervención en la creación de contenidos es también fundamental. Se concluye que, los libros de texto de la asignatura, representan un discurso nacionalista más que didáctico. Con base en la información analizada, se propone un currículo que desarrolle en el alumno las habilidades necesarias para lograr una empatía histórica y un conocimiento significativo.

\section{Palabras claves}

currículo oculto, didáctica, nacionalismo, enseñanza de la historia, historia de México

$$
* * *
$$

The hidden curriculum in the Mexican history books in the Mexican Baccalaureate.

\section{Abstract}

This research analyzes the didactic content of the textbooks of History of Mexico at the baccalaureate level. A qualitative methodology of descriptive type was used. The use of Discourse Analysis made it possible to identify the political, economic and educational context under which the contents of the textbooks are defined, as well as the participation of foreign publishers that are part of this process and whose intervention in the Content creation is also fundamental. It is concluded that the textbooks of the subject represent a nationalist rather than a didactic discourse. Based on the information analyzed, a curriculum is proposed that develops in the student the necessary skills to achieve historical empathy and meaningful knowledge.

\section{Keywords}

hidden curriculum, didactics, nationalism, teaching of history, history of Mexico

Clín \& Asociados. La historia enseñada. Enero-Junio 2019 (28) ISSN 2362-3063 (digital). pp. 33-44 


\section{Introducción.}

En la investigación educativa es necesario diferenciar los libros de texto de los libros escolares. Los libros de texto son concebidos explícitamente para ser usados en una escuela; un libro escolar es un libro utilizado para la enseñanza aunque no haya sido pensado previamente para tal fin. Estudiar los libros de texto es relevante para los investigadores educativos por la importancia que tienen en la enseñanza; según Ibagón (2014:40), son un instrumento que media el currículum ya que permiten que "la pauta oficial se cumpla".

Pocos son los estudios que se han llevado a cabo para analizar el contenido de los libros de texto en Latinoamérica. Los autores Dobaño, Lenkowikz, Román y Rodríguez (2000:165) afirman que: "en general hay muy pocas investigaciones respecto a los libros de texto. Dentro de la escasa producción, los textos de nivel primario han suscitado mayor atención que los de la escuela media". También mencionan:

Sin duda los libros de texto son los materiales curriculares con mayor incidencia para el aprendizaje en el aula. Su rol directivo y configurador de la práctica en el aula los hace diferentes de los demás recursos. También fuera del aula porque la mayor parte del tiempo que los alumnos dedican a los deberes está ocupada por los libros de texto. (Ibídem:170)

La historia reciente de los libros de texto en México inicia el 12 de febrero de 1959 con la fundación de la Comisión Nacional de los Libros de Texto Gratuito (Vargas, 2011). La Secretaría de Educación Pública (SEP), a cargo de Jaime Torres Bodet, presentó una propuesta para que el gobierno mexicano editara y distribuyera gratuitamente libros de texto y cuadernos de trabajo para todos los estudiantes de educación primaria (Greaves, 2001).

Los libros de texto de educación elemental se estructuran a través de ciertos personajes, hechos y lugares para construir sus narrativas del pasado, que deben verse como comunes para todos los mexicanos, siempre convergiendo en presentar a una comunidad mexicana institucional, vinculada y cohesionada, con negativos de nación, definidos por Vargas (2011:515) como "acervos ideológicos y proyectos políticos anteriores que terminan por fortalecer la idea de nación que se exalta".

El modelo teórico, con el que pretendemos abordar el estudio de los libros de texto de Historia en el bachillerato, es tratado por Tosi (2011:476) en su apartado sobre el análisis del discurso, sosteniendo que el libro de texto no es otra cosa más que el vehículo del "conocimiento academizado que las instituciones educativas han de trasmitir [...] en él se representan valores, actitudes y estereotipos e ideologías [...] tiene imposición de los temas y el enfoque pedagógico dado por el currículum oficial", es decir, los conocimientos allí reflejados son los que las instancias del gobierno quieren que se conozca.

El libro de texto es un discurso escolar y como tal, se encuentra bajo el control de los grupos de poder. Los objetos discursivos de ese texto-discurso tienen una carga ideológica. Un libro de texto de Historia no es sólo un instrumento de comunicación de conocimientos, inculca valores e ideas (Ibídem, 2011).

\section{Antecedentes.}

\subsection{Historia de los libros de texto gratuitos en México.}

Según los datos aportados por Greaves (2001), durante el gobierno del presidente López Mateos se pretendía promover en los mexicanos un sentimiento nacionalista que diera como resultado una mayor integración del pueblo. Vio a los libros de texto como el vehículo perfecto para difundir las ideologías del Estado entre todos los sectores de la población. De esta forma, se ejercía el control político que se deseaba, además de tener un mayor control sobre la educación. 
La aparición del libro de texto gratuito provocó fuertes debates entre editores, la Unión de Padres de Familia, el Partido Acción Nacional y la Iglesia. Finalmente, los libros de texto gratuito se quedaban, pero los que pudieran y quisieran pagar libros adicionales que los complementaran podrían hacerlo, mientras el contenido de éstos estuviera autorizado por la SEP (Greaves, 2001).

\subsection{La participación del Estado en el contenido curricular.}

Para Young, el sistema de educación que creó el Estado mexicano después de la Revolución ha buscado inculcar ciertos valores en sus estudiantes. En el caso de los libros considerados, los valores básicos reflejados incluyen los siguientes:

a) el respeto por los "héroes", los líderes, y para el gobierno en general; b) la lealtad a las autoridades, la anulación de las capacidades individuales para cambiar la Historia y la falta de análisis crítico; c) la subordinación de los conflictos internos a favor de la unidad nacional; y d) sumarse a las normas culturales dominantes. (Young, 2010:616-617)

Este autor sostiene que, en los libros de texto gratuito, se idealiza el progreso y "frecuentemente enfatizan la necesidad de mantener la unidad nacional al citar las instancias en que tal unidad se ha roto ocasionando desastres" (Ibídem:604). Ausente en los libros está la reflexión de la historia reciente del país, ausencia que tiene una consecuencia clara en la didáctica de la enseñanza: presentar verdades indiscutibles e irrelevantes que generan poco interés por estudiar la asignatura.

Los libros de texto gratuito evitan criticar a los presidentes y les atribuyen a éstos los logros de la historia de México, no se estudian los movimientos populares, ni a los ciudadanos ordinarios: "el enfoque en los líderes como la vanguardia del cambio social y la falta de énfasis sobre las contribuciones de los actores populares refleja otra tendencia general de los libros: obscurecer la causalidad" (Young, 2010:615). Un estudiante no puede ser un agente positivo de cambio si no entiende el papel de los movimientos populares o las fuerzas sociales en la creación de un problema social o su solución y todo se le atribuye a una personalidad en particular.

La falta de historia social que observamos en los libros no es una situación producto de causas al azar, forma parte de una visión corporativa, de lo que al gobierno mexicano le interesa que se imparta en las aulas mexicanas; los libros de texto son el producto de una visión sexenal, de planes y funcionarios con visiones de corto plazo, siempre cambiantes en función de la renovación de las cúpulas de poder en México (Idem).

En México, entendemos el concepto de "historia nacional" como un conjunto de valores que nos hacen parte de una comunidad homogénea, y asumimos que son propios del "ser mexicano", una idea que todos los gobiernos en turno han buscado colocar en el imaginario colectivo (Vargas, 2012).

Cada gobierno mexicano, ya fuera de la época del desarrollo estabilizador de los años 50 o de la época de Carlos Salinas de Gortari imaginó un pasado común con valores que debían de hacer suyos los habitantes de todo México; en este sentido, los libros de texto son concebidos como una herramienta para formar ciudadanos.

De acuerdo al estudio de Natalia Vargas (2012:917), los libros de texto son, a este respecto, "mecanismos intencionados que registran una versión específica de nación" y tienen la función de exaltar el establecimiento político del estado revolucionario como etapa última en la formación de la nación mexicana; y a través de la categoría pueblo para definir a los nacionales se iguala a la población a nivel racial, pueblo mestizo, y a través de la conciliación de clases.

En la época de Carlos Salinas de Gortari, los libros reflejan un cambio estructural. Para 1992, México se moderniza políticamente y económicamente; en el caso de los libros de texto de ese año se aprecia que sus contenidos pasan a glorificar el liberalismo político y económico, demostrando la relación que hay entre ellos y el contexto ideológico e institucional en el que se publican (Ibídem:918919).

Clín \& Asaciados. La historia enseñada. Enero-Junio 2019 (28) ISSN 2362-3063 (digital), pp. 33-44. UNL - UNLP 


\subsection{Los libros de texto en el bachillerato: su regulación.}

La Ley General de Educación define jurídicamente y regula a la educación, obligando al gobierno a prestarla desde el nivel preescolar, pasando por la primaria, la secundaria y al nivel medio superior. El sistema educativo lo forman planes, programas y todo lo necesario para impartir el servicio educativo (Congreso de la Unión, 2013:6).

El Estado mexicano es el que controla la educación y define los programas y planes de estudio así como el uso de libros de texto gratuito. Para la secundaria, las editoriales privadas tienen que someter sus propuestas de libros de texto para revisión a la SEP, de no tener esa aprobación sus libros no pueden comercializarse. El caso es más complejo en la educación media superior, jurídicamente los particulares pueden imprimirlos sin una aprobación legal, a pesar de ello hay un tipo de regulación:

En las escuelas que imparten la educación media superior, la Secretaría establecerá los mecanismos de colaboración necesarios para que los programas de gestión escolar formulados por las autoridades educativas y los organismos descentralizados, en el ámbito de sus atribuciones, propicien el mantenimiento de elementos comunes. (Idem)

\section{Metodología.}

\subsection{Método.}

En su artículo sobre el análisis del discurso (AD), Sabaj (2008) define a esta disciplina como "un tipo de actividad científica cuyo objeto de estudio son usos reales de la lengua". Los textos se forman de hechos, estos contenidos contribuyen a constituir la realidad social en el momento en que se vuelven significativos; el análisis del discurso explora y analiza cómo es que se llevan a cabo estos procesos.

Por medio de la revisión de la literatura seleccionada y utilizada para nivel bachillerato, en esta investigación se hace una crítica sobre el contenido de los libros de texto de Historia de México, así como de los autores y de las empresas editoriales que participan en su elaboración, analizando el tipo de discurso que manejan y cuál es el currículo oculto que surge como consecuencia.

Empleando la metodología cualitativa, en la cual "el investigador comienza examinando los hechos y en el proceso desarrolla una teoría congruente con lo que observa y registra" (Hernández, 2014:51), este artículo intenta analizar el currículo oculto que se encuentra dentro de los libros de texto a nivel bachillerato en México por medio de las siguientes actividades:

a) Revisión del contenido de los libros de texto a nivel bachillerato.

b) Revisión de diferentes autores expertos en el estudio de la historia de México.

c) Análisis sobre la relación que tiene el contenido de los libros de Historia de México con las casas editoriales que los editan y publican.

d) Determinar qué tipo de discurso es el que se emplea en los libros de texto a nivel bachillerato en cuanto al manejo (o manipulación) de datos sobre la historia de México.

\section{2. Estudio.}

Basada en los estudios de tipo descriptivo, los cuales consisten en "describir fenómenos, situaciones, contextos y sucesos", es decir, "se busca especificar las propiedades, las características y los perfiles de personas, grupos, comunidades, procesos, objetos o cualquier otro fenómeno que se someta a un análisis" (Ibídem:92), esta investigación pretende describir el currículo oculto que está presente en los libros de texto de Historia de México a nivel bachillerato. 


\section{Resultados.}

\subsection{Revisión de editoriales.}

Para los propósitos de establecer los modelos existentes en los libros de Historia de México, se hizo una búsqueda intensiva del material disponible en las librerías del estado de Puebla. Constatamos que hay una alta rotación de títulos de libros y autores, así como paradójicamente, la presencia de algunos clásicos como Historia de México de Carlos Alvear (2003). De la lectura de la muestra extraemos los siguientes puntos:

Los libros de Historia son editados en su mayoría en la ciudad de México por editoriales extranjeras. Entre ellas se encuentran McGraw-Hill (fundada en 1909, sede en Nueva York, EE.UU.), Cengage Learning (Boston, EE.UU.), Prentice Hall (fundada en 1913, sede Nueva Jersey, EE.UU.), Pearson PLC (Londres, Reino Unido), Thomson (fundado en 1950, sede Connecticut, EE.UU.). Estas empresas se caracterizan por ser multinacionales y grandes compañías de manejo de información a nivel mundial, en las cuales, la edición de libros de texto es solo una fracción de sus actividades.

En el caso de Oxford University Press (sede Londres, Inglaterra) la editorial ocupa toda una sección completa de la universidad del mismo nombre, destinada a publicar libros y revistas de todo tipo. Así, las multinacionales que editan los libros de bachillerato en México, son fundamentalmente norteamericanas e inglesas, con filiales presentes en toda Latinoamérica.

A estas empresas multinacionales extranjeras se les unen compañías de mucha tradición en México como Fernández Editores (fundada en 1943, sede en la ciudad de México) o Limusa (hoy LimusaWiley, por haberse asociado con esta última empresa norteamericana). Además de pequeñas compañías que buscan hacerse de un lugar en el mercado, como Grupo Asesor de Formación y Recursos Académicos (GAFRA editores), ubicada también en la ciudad de México.

Pudimos constatar la existencia de modelos regionales de libros de texto, que sobreviven en función de la fuerte estructura académica, de instituciones locales que les da un lugar. Tal es el caso de la Benemérita Universidad Autónoma de Puebla, que al incorporar a sus preparatorias al Sistema Nacional de Bachillerato, en el marco del modelo por competencias, editó una serie de guías educativas para uso exclusivo de sus estudiantes.

Los libros más antiguos normalmente sólo tienen cuestionarios, intercalados en el texto a manera de actividad para hacer más dinámica la lectura. Dependiendo de las necesidades editoriales, los libros pueden presentarse en uno o dos volúmenes, a cargo de uno o más autores. Se constató que muchos de los libros que aparecen en las páginas web de las librerías Sótano, León o Gandhi, no se hallan disponibles a la venta, a menos que se recurra a agentes editoriales: fenómeno que sugiere que las editoriales están desplazando a las librerías como intermediarios de venta.

\subsection{Revisión de los autores.}

En el caso de los autores, el esquema para una editorial privada es un acuerdo de derecho de autor. Estos acuerdos se hacen con licenciados en Historia o carreras afines como Antropología. Algunos, como Salinas (2012), ostentan en su currículo actividades de e-learning y b-learning, relativas a innovación y tecnología educativas. En los libros de edición más reciente ese es un perfil importante, ya que la oferta educativa del libro es complementada con un sitio web de tareas, un disco compacto y tecnología de realidad aumentada, códigos impresos que permiten acceder a videos o sonidos adicionales. 


\subsection{Análisis del contenido de los libros de texto de Historia.}

En cuanto a su estructura, los libros están divididos en bloques que abarcan la historia de México desde las primeras migraciones a América hasta la época reciente (siglo XX). Cada uno ostenta los objetivos del bloque y las competencias a desarrollar.

Las características fundamentales del discurso que manejan los libros de texto de Historia de México en el bachillerato son ocho:

1) Hay una falta constante de contenidos de carácter regional e "historia viva". En el caso del libro Historia de México, de Gloria Delgado de Cantú (2003), llega al extremo de omitir episodios históricos relevantes, como el de los hermanos Serdán (primer alzamiento contra el gobierno de Porfirio Díaz), en la formación de la historia de la Revolución Mexicana. Cuando se explican fenómenos generales como las disputas entre el clero secular y regular en la Nueva España, se desplazan personajes como Juan de Palafox y Mendoza, obispo de Puebla, arzobispo de México, virrey y su enfrentamiento con los jesuitas que podrían explicar mejor esa lucha por el poder, que un planteamiento general de escaso sentido local (Fernández, 2005, p. 102). Dentro de las actividades didácticas planteadas en esta clase de libros, no se contemplan visitas a museos con el fin de reforzar el conocimiento adquirido.

Aún libros como los editados por la Benemérita Universidad Autónoma de Puebla como Historia de México 1, de Pérez (2003), no planean actividades de "historia viva" para alumnos, como visitas a lugares históricos locales. Esto tiene como consecuencia una falta de conexión entre los alumnos y los testimonios históricos de sus comunidades que les podrían ayudar a entender mejor su propia historia; difícilmente los educandos podrán tener una conciencia cívica y ética de su región si no correlacionan su historia personal con la de su comunidad, primer paso para entender la historia nacional.

2) En procesos históricos como la Conquista, se describe una situación ideal de los grupos menos favorecidos. Se escribe sobre la situación de los indígenas justificando el dominio español:

No pagaban diezmos ni contribuciones, pero sí tributos. Cuando acudían a los tribunales, el procedimiento que se seguía era más fácil que el seguido por el de los españoles [...] para poner a los indios a salvo de malas acciones y explotaciones, la ley ordenaba que en sus pueblos no se avecindaran ni españoles, ni mestizos, ni negros, ni mulatos. (Alvear, 2003:124)

No se pone suficiente distancia en una situación que teóricamente describen las Leyes de Indias, la legislación española para América y la realidad, en la que los indígenas no podían montar a caballo, portar armas y en la que por muchas razones, en las que podemos situar sus condiciones de vida, se rebelaban constantemente. $\mathrm{Ni}$ el manejo de citas, como cuando se escoge a José Vasconcelos describiendo la Conquista como una historia de:

Capitanes y monjes de la Conquista, guerreros y civilizadores [...] la de América una última cruzada en la que los caballeros, flor de Europa, después de rebasar sobre el moro, ganaron para la cristiandad, con las naciones de América, el dominio del planeta, la supremacía del futuro. (Pérez, 2003:85-86)

3) Una dialéctica de enemigos de la formación de un Estado nacional contra partidarios del mismo. El enfrentamiento entre liberales y conservadores en el siglo XIX mexicano explica lo anterior, de manera general los conservadores son caricaturizados como enemigos del progreso al etiquetarlos: "El nombre de conservadores se debe a que a toda costa quieren conservar todos los privilegios que habían disfrutado durante la Colonia. Se les llama también reaccionarios porque son una fuerza política que se opone al progreso, y cangrejos", los liberales por su parte tienen "su origen en los criollos, indígenas y mestizos con educación, a los que el gobierno español tenía marginados por su origen americano" (Barroy, 2000:159). La referencia de "cangrejos" se debe a unos versos decimonónicos que los liberales impusieron a los conservadores “cangrejos al combate, cangrejos al compás: un paso pa' [sic] adelante, un paso para atrás" (Pérez, 2003:151). Ese tipo de dialéctica es profundamente ahistórica y descontextualizante. Los conservadores también buscaban industrializar México y fundaron 
instituciones como el Banco de Avío para tal fin, de ninguna manera se oponían al progreso material del país. No considera el contexto: no había bandos homogéneos enfrentados entre sí. Lo mismo había liberales que en su momento fueron conservadores, que conservadores que habían estado en el bando opuesto. Antonio López de Santa Anna es un buen ejemplo: en la presidencia cuatro veces, siendo liberal y conservador, o el liberal Lorenzo de Zavala convirtiéndose en vicepresidente de la Texas anglosajona.

4) Una idea de progreso inevitable en un país en el que los partidarios del Estado nacional se imponen. Así, México en el siglo XIX era víctima de la desunión:

Después de la firma del Acta de Independencia, el país se volvió el escenario de grandes luchas internas. Los personajes que participaron en la última etapa de la lucha armada, junto con los partidos en disputa, liberales y conservadores, no se ponían de acuerdo en quién debía gobernar el nuevo país, así que se fueron alternando varios gobernantes con ideologías diferentes, algunos llegaron incluso a nombrarse emperadores [uno]. Todo esto causó un caos tanto en lo económico como en lo social en nuestro país [...] Fue hasta que los gobiernos liberales se apoderaron de la presidencia y lograron cierta estabilidad en todos los sectores. (Hernández \& Gómez, 2015:32)

Los liberales tomaron el poder en 1861, a lo que siguió la segunda intervención francesa (18621867), los alzamientos militares de La Noria y Tuxtepec (1871 y 1876), de ninguna manera se puede afirmar que lograran "estabilidad" o "paz," eso llegaría mucho tiempo después (el Porfiriato se consolida hasta 1884). La idea de un progreso lineal en la historia sin retrocesos ni particularidades, como el Porfiriato (1876-1911) en que las libertades políticas y el respeto al voto mostraron una notable ausencia, no abona en la comprensión ni didáctica de los hechos históricos, existe sólo para justificar la idea de un gobierno y un proyecto nacional actual, que se supone heredero de ese pasado.

En el caso de la Revolución Mexicana, Álvaro Obregón y Plutarco Elías Calles son presentados como la iniciación del México moderno, un "logro" que consiguieron en función de sus méritos personales. En el caso del primero, se escribe que "el camino que habría de tomar Obregón para dar solución a los problemas antagónicos de la clase trabajadora con el sector empresarial, sería el de la conciliación de clases" con "el equilibrio [que] sólo podía [darse] en aquellos tiempos posteriores a la Revolución” (Delgado de Cantú, 2003:103-104). Elías Calles completa la modernización política del país con la fundación del Partido Nacional Revolucionario (PNR antecesor del PRI) cuyo "proyecto de partido se debía sin embargo, a los dirigentes callistas y fue ante todo la obra de un hombre, el general Calles y, en buena medida a la expresión de su pensamiento" (Ibídem:147). La consecuencia es la presidencia de un hombre como Miguel Alemán (1946-1952) cuyo:

Gobierno [...] representa la culminación del proceso constitucional iniciado en el Maximato, durante el cual los subsecuentes gobiernos mexicanos tuvieron que luchar por diversos medios, conciliatorios en la mayoría de los casos, para hacer frente a los conflictos entre grupos con ideologías diferentes e incluso opuestas. (Delgado de Cantú, 2003:265)

Ese progreso constitucional es muy discutible. No hay evidencia de que un hombre como Obregón, que modificó la Constitución para reelegirse y aumentar su período presidencial y que eliminó a sus rivales físicamente, pensara que el país iba a terminar con un sistema presidencialista como el de Alemán. Ni Calles, que creó el PNR con la intención de tener poder para él, a través de la manipulación de presidentes títeres en el período histórico conocido como el Maximato.

5) La falta de unión de la sociedad hacia ese proyecto nacional es causa del fracaso del país. En el libro de Historia de México se establece una analogía entre la intervención norteamericana de 1847 y el 5 de mayo de 1862, en la primera:

Para México, la frustración, la derrota, el desaliento al ver que diez mil soldados fueron capaces de vencer a todo un pueblo que durante cuarenta años no había tenido paz. A un país al que el

Clío \& Asaciados. La historia enseñada. Enero-Junio 2019 (28) ISSN 2362-3063 (digital), pp. 33-44. UNL - UNLP 
egoísmo y las luchas internas habían destruido y acabado con todas sus riquezas y valores, y ahora, sin más, la mitad de su territorio. (Barroy, 2000:145)

El gobierno había fracasado en defender al país por su pobreza, por el contrario "la aristocracia y el alto clero que tenían en su poder el $80 \%$ de la propiedad territorial", no se habían sumado. Cuando la unión se logra: "El 5 de mayo, la verdad es otra. Los mexicanos habían derrotado al mejor ejército del mundo. Las consecuencias de esta victoria mexicana y derrota francesa fueron trascendentales. México era otro país, no como el que fue derrotado por Estados Unidos. Sus gobernantes eran otros, su moral también” (Ibídem:147, 167).

6) Falta de crítica a personajes icónicos de la historia nacional. El caso de Venustiano Carranza es significativo. Su trascendencia se resume en el "proyecto para reformar la Constitución de 1857" (Delgado de Cantú, 2003:72), la Constitución "fue promulgada oficialmente el 5 de febrero de 1917 y representa a la incorporación de México a la modernidad política [...] es en esencia el principal legado de la Revolución Mexicana" (Flores, 2004:109). La Constitución pasó a ser "lo más revolucionario de la Revolución. Todo lo que se construiría en un futuro, está basado en lo que el presidente Carranza, junto con algunos diputados [...] establecieron en su Carta Magna" (Hernández \& Gómez, 2015:130). En realidad, la explicación de que, muchos de sus artículos, como el $27^{\circ}$ constitucional nunca se aplicaron a los intereses extranjeros, en el petróleo o minas, brilla por su ausencia. Ni que el mismo Carranza, una vez derrotados sus enemigos Zapata y Villa, frenó el reparto agrario o comenzó la represión de los obreros. En cuanto a cómo veía la sociedad a Carranza hay pocas referencias, se mencionan dificultades económicas y un proceso inflacionario, que de ninguna manera se relacionan con la emisión desaforada de papel moneda, producto de sus decisiones de gobierno (Delgado de Cantú, 2003). En el momento en que Carranza debe dejar el poder, en las elecciones de 1920, se da un conflicto explicado de la siguiente manera:

Ignacio Bonillas [...] era un civil que aparentemente sería apoyado por Carranza para sucederle, no obstante, importantes dirigentes del norte, como el general Álvaro Obregón (1880-1928), el gobernador de Sonora Adolfo de la Huerta [...] conspiraron en contra de quién antes habían servido, el argumento era que Carranza no respetaría el voto popular en las elecciones de 1920. (Hernández \& Gómez, 2015:129)

Gloria Delgado de Cantú (2003:82) prefiere explicar el conflicto orientándolo a una rivalidad entre militares que hizo que Carranza se inclinara por el civilismo y "había favorecido la candidatura presidencial del ingeniero Bonillas, pero esta decisión acrecentó el conflicto y canalizó la rebelión en contra de Carranza". En realidad, Carranza buscaba perpetuarse en el poder, a través de Bonillas, ello y el encarcelamiento de Obregón, la represión a las clases obreras y la falta de apoyo al reparto agrario.

7) Es notable ver cómo los libros de texto minimizan los movimientos sociales en la época colonial. Comienzan a aparecer de una manera muy breve en la época de la Independencia en el caso de Guanajuato: La guarnición militar y los burgueses españoles se refugiaron en la alhóndiga (lugar donde antiguamente se guardaba y comerciaba el grano) aunque no pudieron mantenerse atrincherados por mucho tiempo, ya que la multitud cayó sobre ellos y decapitaron a algunos (Cuchí, Gómez \& Villavicencio, 2017:182-283).

En realidad, la violencia en contra de la población española de Guanajuato fue más general y amplia, y podría entenderse mejor si los libros dieran su respectivo lugar a los motines coloniales, para comprenderse de una mejor manera los orígenes sociales de esa animadversión de razas que se dio en Guanajuato. O como en el caso de la ciudad de Guadalajara donde los indígenas estaban reaccionando a la explotación colonial española. 
En el caso de la modernización reciente en la historia de México los movimientos sociales son prácticamente inexistentes. Es notable que se omitan agentes históricos como Othón Salazar, en el movimiento magisterial de 1958 (Flores, 2004). Cuando se mencionan estos sucesos y a sus personajes, se hace de manera breve y se descontextualizan las razones de su surgimiento. Los libros de texto, en el caso de Miguel Alemán, suelen enaltecer su obra pública a la vez que omiten los movimientos sociales en su época:

Empleo de recursos para impresionar mediante la obra pública generó la creencia de que el dinero se estaba utilizando correctamente en el país [...] esto le trajo a Miguel Alemán Valdés un gran número de adeptos y se hizo acreedor de mucha simpatía por parte de la opinión pública extranjera [...] el aspecto negativo fue el aumento de la deuda externa, problema que se insertaría de por vida en las administraciones posteriores. (Hernández \& Gómez, 2015:162)

8) Falta de crítica a la historia reciente de México. Particularmente, en el caso del movimiento de 1968, se mantiene una visión que privilegia acontecimientos externos a internos en el origen del fenómeno que escasamente se explica:

Pues en 1968, año en el cual, en México -en concordancia o en simultaneidad con lo ocurrido en otras partes del mundo-, se dejó sentir una inquietud que, iniciada por un incidente de violencia estudiantil, tomó un cuerpo inusitado, movilizó a mucha gente, se crearon tensiones graves, hubo influencias extremistas y los hechos culminaron el 2 de octubre con gran derramamiento de sangre en la plaza de las tres culturas en la capital nacional. (Alvear, 2003:316)

No hay una sola referencia a los granaderos que entraron a la Preparatoria San Ildefonso, ni a la situación del país, ni en qué consistió ese "derramamiento de sangre" del 2 de octubre. Parecen desconocer el papel del gobierno en el conflicto. El libro Historia de México 2 es más claro al respecto:

En México todo parecía indicar que se cumplían las condiciones para que lo anterior ocurriera también, descontento social, desigualdad, ideas radicales y ahora nuevos ídolos [...] El Che Guevara, Ho Chi Minh y Fidel Castro, por mencionar algunos. Aunque no existen datos que confirmen una intervención manifiesta de la Unión Soviética para alimentar a estos grupos disidentes, la situación de la Guerra Fría, extendida en la comunidad internacional, sugiere que en efecto, hubo apoyos para nutrir a ciertos grupos comunistas en México. (Hernández \& Gómez, 2015:170)

La responsabilidad del gobierno, es diluida al afirmar que, en el 2 de octubre "la presencia del ejército federal, cientos de estudiantes, obreros, profesores, electricistas y grupos paramilitares (Los Halcones y el Escuadrón Olimpia) se involucraron en uno de los más tristes episodios de la violencia en la historia del país" (Ibídem:171), una declaración neutra que no explica el hecho de que el gobierno fue el responsable de la matanza de 1968.

En el caso de Carlos Salinas de Gortari y su gobierno en México (1988-1994), su gran legado pasa a ser el Tratado de Libre Comercio, cuya puesta en marcha "nos obliga a trabajar con ahínco para ofrecer una mayor competitividad e integrarnos con Estados Unidos a la realidad que implica el mercado más grande del mundo" (Flores, 2004:410), así:

La política económica del salinismo favoreció la integración de México en el mercado mundial, auspiciando las posibilidades de crecimiento, a condición de trabajar incesantemente para hacer posible el desarrollo de las fuerzas productivas y el mejoramiento gradual de las condiciones de vida, lo que implica necesariamente una distribución equitativa de la riqueza entre la población, que corresponderá a la moralidad de la administración en turno. (Ibídem:411)

Ni el "trabajo incesante" ni la "moralidad de los gobernantes" determina la distribución equitativa de la riqueza en la población. La integración comercial ya tenía efectos negativos en la planta

Clío \& Asaciados. La historia enseñada. Enero-Junio 2019 (28) ISSN 2362-3063 (digital), pp. 33-44. UNL - UNLP 
productiva nacional en la misma época en la que gobernaba Salinas y provocaba cuestionamientos, que no han dejado de crecer con el tiempo.

\section{Conclusiones.}

Una vez revisada la información en los libros de texto y de haber leído la opinión de diversos autores con respecto al estado actual del contenido de estos libros y del aprendizaje que se obtiene de ellos, fue posible realizar un análisis del discurso que arrojó las siguientes conclusiones:

Los libros de texto de Historia para el bachillerato, aunque no están impresos directamente por el gobierno sino por instancias privadas, representan un discurso nacional y corporativo. Ese discurso presenta un fuerte contenido ideológico más que didáctico, con una serie de valores, actitudes y estereotipos que imponen un enfoque pedagógico distinto al que un modelo por competencias basado en el constructivismo social debería de tener. No solamente es el hecho de construir narrativas con personajes y lugares que impone un currículo oficial en la materia, la manera como se presentan distorsiona el aprendizaje.

Particularmente, la exclusión de movimientos sociales y la falta de explicación de fenómenos de la vida reciente de México, reducen la capacidad crítica del alumno, así como de valorar las diferencias sociales, políticas, económicas y las desigualdades que inducen. En lugar de ello, tenemos simplificaciones, las explicaciones se centran en torno a personalidades y a lugares alejados de la vida normal del educando. En el libro Historia de México II, de Fernández (2005:96), la transformación de la personalidad del presidente Porfirio Díaz pasa a ser obra de su esposa: "Carmelita Romero Rubio fue en gran medida la que «creó» la figura de Díaz preparado, inteligente y calculador".

La falta de reflexión del presente en el estudio del pasado presenta a la Historia como un conjunto de hechos no sujetos a discusión y sin importancia en la vida común del educando. La historia no pasa a ser la representación del pasado de la sociedad, sino sólo de unos cuantos hombres, personajes que pasan a ser concebidos como los agentes primarios de la historia, pasando por alto la capacidad que cualquier persona tiene de crear el cambio en una sociedad, situación que pasa a reducir el significado de la materia para el educando que comienza a considerarla ajena a él.

La idea de un progreso natural y lineal en la historia de México, en el que se omite que el pasado es un objeto "vivo", sujeto a polémica, dificulta el entendimiento de la causalidad histórica y desalienta al estudiante a convertirse en un factor de cambio social, ya que el progreso natural de México, siguiendo este enfoque, lleva al país tarde o temprano a una situación mejor.

La causalidad debería presentarse como una explicación social clara del origen de los fenómenos sociales, que ayudará al estudiante a establecer una conexión clara entre los hechos históricos, locales, regionales, nacionales y mundiales. El contenido de los libros de Historia dificulta encontrar las relaciones causales de los hechos históricos.

Los libros de texto en el bachillerato tienen una estructura que privilegia la información fáctica antes que los conceptos y procedimientos. Esto dificulta la creación de un tipo de historia más analítica y estructurada. Los personajes, lugares y hechos mostrados en los libros de texto pertenecen más a la historia nacional más que a la local y la estructura narrativa de los textos plantea problemas de interpretación para fines explicativos regionales.

Así es el caso de muchos estudios empíricos que concluyen que, a pesar de todas las reformas curriculares que se han hecho, el constructivismo tiene todavía mucho camino por recorrer en las aulas en México, encontrando que:

los alumnos tienen un conocimiento declarativo y no procedimental de los hechos históricos, dado que pueden nombrar o describir, pero no pueden encontrar relaciones causales [...] A los alumnos les resultó difícil el poder establecer relaciones causales, identificar elementos de cambio y continuidad simples a partir de las transformaciones personales, sociales y naturales. (DíazBarriga, García y Toral, 2008:152) 
La mayor crítica que puede hacerse, para los propósitos de esta investigación, a este género de libros de texto es una falta de interpretación social a partir de los procesos históricos locales y no incluir narrativas que en sus contenidos incentiven a los alumnos a participar con una conciencia cívica y ética en la vida de su comunidad y región, competencias que el modelo del Sistema Nacional de Bachillerato establece que tienen que impartirse en la asignatura (Diario Oficial de la Federación, 2008).

En sus artículos, Lerner (1995) y Carretero y Montanero (2008), coinciden en que, en México, la enseñanza y el aprendizaje de la materia no ha superado el ámbito memorístico y cronológico y ese "pensar históricamente" no se ha alcanzado.

No es cuestión de negar la existencia de una historia nacional de la que evidentemente todos somos parte, sino de enfocarla de otra manera. En el caso de los libros de texto, mediante un enfoque micro histórico, se puede favorecer el aprendizaje en función de la realidad concreta de sociedades plurales que forman nuestro país. Los contenidos discursivos y el aprendizaje de la materia de Historia de México solo pueden tener éxito práctico reconociendo esa realidad diversa, no tratando de imponer conceptos históricos que no corresponden a ella.

Consideramos que la labor de diseño editorial de los libros de texto debería estar en manos de las comunidades educativas locales. Las modernas tecnologías digitales permiten crear versiones en formatos libres que podrían contribuir a una enseñanza más plural, menos centralizada y más significativa para los estudiantes en las regiones de México.

En opinión de Lamoneda (1998:102), aunque hay un acuerdo en contra de la historia política y su enseñanza en el bachillerato, ésta continúa presente, reduciendo el significado de la materia, los estudiantes "no saben de dónde proceden los conocimientos ni los conceptos que reciben en el salón de clase, tampoco cómo se construye el conocimiento histórico, ni qué se construye". Díaz-Barriga Arceo (1998:8), por su parte, afirma que: "Los alumnos tienden a ver la historia como una colección de hechos que tienen que ver con un pasado, una forma de conocimiento «muerto» [...] los alumnos no parecen captar la posibilidad de una proyección del conocimiento histórico sobre su presente e incluso sobre su futuro".

Para crear una adecuada didáctica de la historia se debe partir de crear habilidades cognitivas en los alumnos, éstas son el llamado "tiempo histórico: que no se define como recordar un hecho clave, sino como:

La construcción de categorías y nociones temporales (sucesión, simultaneidad, continuidad) [...] la adquisición de instrumentos y códigos que le permitan estimar el tiempo histórico [...] la comprensión y utilización del sistema de representación icónica del tiempo histórico [...] el uso correcto de indicadores básicos de tiempo. (Ibídem:10-11)

Una estrategia que esta autora retoma, para lograr lo anterior, se refiere a lo siguiente:

El empleo del pasado próximo del alumno como punto de partida y referente básico en la construcción de esta noción. Partiendo de hechos significativos de la vida del propio estudiante, se le puede ayudar a estructurar en niveles paralelos el tiempo personal, el tiempo familiar, el tiempo local y el tiempo nacional e internacional. (Díaz-Barriga Arceo, 1998:13)

El uso del pasado próximo ayuda a desarrollar la habilidad de empatía histórica, ésta: “está relacionada con la posibilidad de entender (no necesariamente de compartir o avalar) las acciones de los hombres del pasado, desde la perspectiva de ese pasado" (Ibídem:14). Como docentes e investigadores, podemos afirmar que la empatía histórica es una habilidad cognitiva fundamental para desarrollar en los estudiantes de bachillerato. Es más fácil aprender un conocimiento significativo que entendemos, al cual vemos un sentido, que una colección de datos de historia política, cuya importancia en nuestra vida no alcanzamos a comprender. El reto de crear mejores libros de texto sigue presente para los investigadores educativos actuales.

Clín \& Asaciados. La historia enseñada. Enero-Junio 2019 (28) ISSN 2362-3063 (digital), pp. 33-44. UNL - UNLP 


\section{Bibliografía}

Alvear, L. (2003). Histtria de Méxica. Méxica: Limusa.

Barroy, H. (2000). Histaria de Méxica. Méxica: Mc Graw Hill Higher Education.

Carretero, M. \& Montanero, M. (2008). Enseñanza y aprendizaje de la historia: aspectos cognitivos y culturales. Cultura y Educací́n, 20, 133-142.

Congreso de la Unión (2013). Ley general de educación. Recuperada de https://www.sep.gob.mx/work/models/sep//Resource/558c2c24-Db12-4676-ad90-

8ab780866184/ley_general_educacion.pdf

Cuchí, V.; Gómez, R. \& Villavicencio, N. (2017). Historia de Méxica 2. México: Gafra.

Delgado de Cantú, G. (2003). Historia de Méxica 2. Méxica: Prentice Hall.

Diario Oficial de la Federación (2008). Acuerdo 444. Recuperado de http://daf.gab.mx/nota_to doc.php?codnota=5064950

Díaz-Barriga Arceo, F. (1998). Una aportación a la didáctica de la historia. La enseñanza-aprendizaje de habilidades cognitivas en el bachillerato. Perfiles educativas, 82, 40-66.

Díaz-Barriga, F.; García, J. \& Toral, P. (2008). La comprensión de la noción de tiempo histórico en estudiantes mexicanas de primaria y bachillerato. Cultura y Educación, 20(2), 143-160.

Dobaño, F.; Lenkowikz, M.; Román, M. \& Rodríguez, M. (2000). Una nueva mirada sobre la historia económica y sacial. Su presentación en los libros de texto escolares de la última década. Clía \& Asaciados. La Historia Enseñada, 5, I65-188.

Fernández, I. (2005). Histtria de Méxica I. Méxica: Pearson Prentice Hall.

Flores, R. (2004). Historia de Méxica 2. Méxica: Thamson.

Greaves, L. (200I). Política educativa y libros de texto gratuitas. Una polémica en torno al control por la educación. Revista Mexicana de Investigación Educativa, B(I2), 205-221.

Hernández, M. \& Gómez, R. (2015). Historia de Méxica 2. Méxica: Gafra.

Hernández, R. (2014). Metodalogía de la investigación. Méxica: McGraw-Hill Education.

lbagón, M. (2014). Los textas escolares y la enseñanza de la historia: elementos teóricos para entender su relación. Hajas y Hablas, 11, 37-46.

Lamoneda, H. (1998). ¿Cómo enseñamos historia en el nivel medio superior? Revista Mexicana de lnvestigación Educativa, 3, IDI-1I2.

Lerner, S. (1995). Propuestas para el desarrollo de la didáctica de la historia en México. Perfiles educativas, 67, s/d.

Pérez, J. (2003). Histaria de Méxica I. Méxica: BUAP.

Sabaj, Q. (2008). Tipos lingüísticos de análisis del discurso (ad) o un intento preliminar para un orden en el caos. Revista de Lingüistica Teórica y Aplicada, 46(2), III-136.

Salinas, L. (2012). Historia de Méxica l. Méxica: Fernández Editores.

Tosi, ᄃ. (2Dil). El texto escolar como objeto de análisis. Un recarrido a través de los estudias ideológicas, didácticas, editariales y lingüísticas. Lenguaje, 39(2), 469-500.

Vargas, E. (2011). La Historia de México en los libros de texto gratuita: evidencia de las transformaciones en los modelos de integración nacional. Revista Mexicana de Investigación Educativa, IG(49), 489-523.

Vargas, N. (2012). Historia de la enseñanza de la historia. Los libros escolares de la Historia Nacional como unidad de análisis en la investigación sociológica del Estado. Memorias del Tercer Encuentro Nacional de Dacencia, Difusión y Enseñanza de la Historia y Primer Encuentro Internacional de la Enseñanza de la Historia (908-929). México: Universidad Pedagógica Nacional.

Young, K. (2010). Progresa, patria y héraes: Una crítica del currículo de historia en Méxica. Revista Mexicana de Investigación Educativa, 15(45), 599-620. 